2019-12-01

\title{
Marine pollution from pyroplastics
}

\section{Turner, Andrew}

http://hdl.handle.net/10026.1/14834

10.1016/j.scitotenv.2019.133610

Science of the Total Environment

Elsevier

All content in PEARL is protected by copyright law. Author manuscripts are made available in accordance with publisher policies. Please cite only the published version using the details provided on the item record or document. In the absence of an open licence (e.g. Creative Commons), permissions for further reuse of content should be sought from the publisher or author. 


\section{Marine pollution from pyroplastics}

2 Andrew Turner*a, Claire Wallerstein ${ }^{b}$, Rob Arnold ${ }^{b}$, Delia Webb

3

4 aSchool of Geography, Earth and Environmental Sciences,

5 University of Plymouth

$6 \quad$ Drake Circus

7 Plymouth PL4 8AA, UK

8 aturner@plymouth.ac.uk

9

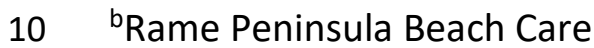

1156 Fore Street

12 Kingsand

13 Torpoint PL10 1NA, UK

14

15 'Friends of Portheras Cove

16 Village Community Centre

17 Pendeen TR19 7SE, UK

18

19

Accepted 25 ${ }^{\text {th }}$ July 2019

20

https://doi.org/10.1016/j.scitotenv.2019.13 
Items of marine plastic litter are conventionally classified as primary or secondary, depending on whether they are distinct objects or angular fragments, respectively. "Pyroplastic" is an additional type of plastic litter that is described here, based on observations made on beached samples from south west England. Pyroplastics are derived from the informal or more organised burning of manufactured plastics and may be angular "plastiglomerates", comprising pieces of plastic debris within a matrix, or rounded plastic "pebbles", where agglomerated material has been weathered and smoothed into more brittle and neutrally-coloured geogenic-looking clasts. Beached pyroplastics are usually positively buoyant because of a polyethylene or polypropylene matrix, and exhibit a bimodal mass distribution attributed to the breakage of larger clasts (> $20 \mathrm{~mm}$ ) into smaller fragments $(<5 \mathrm{~mm})$. XRF analysis reveals variable quantities of $\mathrm{Pb}$ in the matrix (up to $7500 \mu \mathrm{g} \mathrm{g}^{-1}$ ), often in the presence of $\mathrm{Cr}$, implying that material in many samples pre-dates restrictions on the use of lead chromate. Low concentrations of $\mathrm{Br}$ and $\mathrm{Sb}$ relative to pieces of manufactured plastics in the marine environment suggest that pyroplastics are not directly or indirectly derived from electronic plastic. Calcareous worm tubes on the surfaces of pyroplastics dense enough to be temporarily submerged in the circalittoral zone are enriched in $\mathrm{Pb}$, suggesting that constituents within the matrix are partly bioavailable. Evading ready detection due to their striking visual similarity to geogenic material, pyroplastics may contribute to an underestimation of the stock of beached plastics in many cases.

Keywords: pyroplastic; plastiglomerates; marine litter; weathering; XRF; lead

\section{Introduction}

Marine pollution from plastics is a growing global problem that results from a complex interplay between demand, consumption, disposal and recycling of the material. Because of their persistence, hydrophobicity and low density, plastics in the marine environment have a variety of wellestablished economic, visual and ecological impacts (Wilcox et al., 2016; Krelling et al., 2017) in addition to emerging potential consequences on health and food security (Santillo et al., 2017; Barboza et al., 2018).

While suspended, deposited or beached, plastics undergo gradual and progressive mechanical, chemical and photo-oxidative breakdown (Song et al., 2017; Cai et al., 2018). Consequently, plastics may be classified as primary, bearing the recognisable integrity of the original plastic structure, or secondary, where objects have been broken down into smaller fragments or pieces whose primary 
source is often difficult to establish. Examples of primary plastics include shot-gun cartridges, bottles and bottle tops, straws, cutlery, pellets, pens, cigarette lighters, cotton buds, food packages, toys, strapping and rope.

Recently, an additional type of non-manufactured marine plastic was described by Corcoran et al. (2014). "Plastiglomerates" are indurated, multi-composite materials made hard by the agglutination of rock and other materials with molten plastic, the source of the latter being attributed to the informal, open (e.g. campfire) burning of plastic waste. Plastiglomerates may be classified as in situ, where the material is adhered to a rocky substrate, or clastic, where conglomerates are discrete entities. This type of marine plastic is, therefore, composed of a melted polymeric matrix of unknown origin(s) that encapsulates sand, rock, shell fragments, wood and various pieces of anthropogenic debris, with a resultant bulk density of about 2 to $3 \mathrm{~g} \mathrm{~cm}^{-3}$.

Over the past two years, the Cornwall Plastic Pollution Coalition, a group of voluntary organisations, has reported the occurrence of plastics on beaches throughout the county of Cornwall, south west England, that have undergone burning in situ or ex situ. Their appearance is similar to the plastiglomerates described by Corcoran et al. (2014) but encapsulated material is usually plastic (rather than rock or sand) and many samples do not appear to have agglomerated any significant quantities of extraneous material. Consequently, these samples have a relatively low bulk density and most will float in sea water. "Pyroplastics", as they are hereafter referred to, may be encrusted on rocky outcrops towards the back beach and cliffs, or encountered along the strandline as distinct clasts, with crusts eventually breaking off and becoming a series of clasts.

In the present paper, a variety of pyroplastics collected from various beaches are described and defined, with particular emphasis on material retrieved from Whitsand Bay, a large, protected, sandy and southwest-facing embayment to the west of Plymouth (Uncles et al., 2015; Figure 1). A selection of samples is subject to analysis by Fourier Transform Infrared (FTIR) spectrometry in order to define their polymeric makeup and by $\mathrm{x}$-ray fluorescence (XRF) spectrometry in order to identify inorganic additives and co-contaminants. Attempts are made to determine the origin and age of pyroplastics and to evaluate their potential environmental impacts and chemical hazards.

\section{Methods}

Through calls and descriptions on social media from mid-2018 to early 2019, pyroplastics were reported on and retrieved from sandy beaches throughout the county of Cornwall, including Whitsand Bay (Figure 1), and then from places farther afield, both in the UK and overseas. As part of 
organised beach cleans or from informal beach-combing about 400 samples out of several thousand collected from the strandline, foreshore and rocky outcrops were forwarded to the University of Plymouth. Recording the abundance of pyroplastics was not an objective of the present study and was confounded by the difficulty in identifying material (especially where they assumed a geological appearance), but during a systematic clean of a beach on Whitsand Bay it was noted that several samples were often retrieved per metre of strandline.

In the laboratory, a subset of 165 samples from the beaches of Whitsand Bay and 30 samples collected from elsewhere were classified by density according to whether or not they floated in tap water at room temperature contained in a $30 \mathrm{~cm}$ diameter glass dish or a half-filled 30-L laboratory sink. Cleaned and dried samples were then photographed, weighed on a five-figure Sartorius Genius balance and measured for primary diameter (longest axis; $d_{1}$ ) and secondary diameter (shortest axis but through the thickest part; $d_{2}$ ) using digital callipers. Samples were coded for colour (or colours) and the abundance and nature of encapsulated materials.

Samples were subsequently analysed for various elements that are indicative of additives, contaminants and extraneous material $(\mathrm{Br}, \mathrm{Cd}, \mathrm{Cl}, \mathrm{Cr}, \mathrm{Cu}, \mathrm{Fe}, \mathrm{Pb}, \mathrm{Sb}, \mathrm{Zn})$ using a battery-operated Niton XL3t He GOLDD+ XRF spectrometer described in detail elsewhere (Turner and Solman, 2016). The instrument was configured nose upwards in a laboratory test-stand and activated remotely by a laptop. The region of the sample to be probed (usually the central part with the flattest and smoothest face) was placed above the detector window and counted in a standardless plastics mode with thickness correction (where sample thickness was less than $10 \mathrm{~mm}$ ) for 20 seconds at $40 \mu \mathrm{A}$ and $50 \mathrm{kVp}$ and 10 seconds at $100 \mu \mathrm{A}$ and $20 \mathrm{kVp}$. Spectra arising from sample counting were quantified by fundamental parameter coefficients to yield elemental concentrations in $\mu \mathrm{g} \mathrm{g}^{-1}$ and a measurement error of $2 \sigma$ (95\% confidence). For samples too large to fit in the test stand $(>20 \mathrm{~cm}$ in length) measurements were made likewise but the instrument was operated hand-held using the trigger mechanism with samples cradled in a folded radiation apron placed on a stainless steel bench. Elements were also determined in the calcareous worm tubes attached to two pyroplastics and, as a non-plastic control of similar density, a tarball. Here, the crushed contents of five $\sim 100 \mathrm{mg}$ deposits scraped from each sample were analysed by XRF in a higher density soils mode for counting periods of 45 seconds at $40 \mu \mathrm{A}$ and $50 \mathrm{kVp}$ and 15 seconds at $100 \mu \mathrm{A}$ and $20 \mathrm{kVp}$.

For quality assurance and instrument performance purposes, two $13 \mathrm{~mm}$-thick Niton reference plastics that had been impregnated with various elements (PN 180-554 batch SN PE-071-N and PN 180-619 LOT\#T-18) were analysed at regular intervals throughout each measurement session; concentrations returned by the XRF were always within 15\% (and usually within 10\%) of certified 
values. Precision, evaluated by quintuplicate measurements of the same area of six samples of varying size, colour and appearance, ranged from $<5 \%$ for $\mathrm{Cl}, \mathrm{Fe}$ and $\mathrm{Pb}$ to about $15 \%$ for $\mathrm{Cd}$ and $\mathrm{Sb}$.

Thirty of the Whitsand pyroplastics and five samples collected elsewhere that had been characterised above were analysed by attenuated total reflectance FTIR (ATR-FTIR) spectrometry using a Bruker Vertex 70. A stainless steel scalpel was employed to scrape a piece of a few $\mathrm{mg}$ from different regions of the surface and, in some cases, the subsurface (below $1 \mathrm{~mm}$ ). Samples were clamped against the diamond crystal before spectra were acquired with 16 scans in the region 4000 to $600 \mathrm{~cm}^{-1}$ and at a resolution of $4 \mathrm{~cm}^{-1}$. After being smoothed, baseline-corrected and normalised via Bruker OPUS 7 software, spectra were compared with libraries of reference spectra for the identification of component polymers and were visually inspected for signs of polymer modification.

\section{Results}

\subsection{Visual and physical characteristics}

Pyroplastics were supplied from beaches in Cornwall and from the Orkneys (Scotland), County Kerry (Ireland) and north west Spain, and were reported on the coast of Vancouver (Canada). Samples were broadly similar in appearance, colour, size range and chemical makeup, but for the purposes of further classification and quantification, pyroplastics are restricted to those from the beaches of Whitsand Bay where a greater number had been collected in a more systematic manner.

Figure 2 and Figure S1 illustrate pyroplastics collected from Whitsand Bay from which a subset was forwarded to the University, while Figure 3 shows six larger clasts, graded according to degree of agglomeration and angularity, that had been sampled from this subset. Pyroplastics are distinctly different from manufactured plastics, having a geological or industrial appearance, often being agglomerated and heterogeneous, and generally being considerably thicker and less angular than secondary fragments. Pyroplastics are defined by an amorphous matrix formed by the burning or melting of plastic that is usually characterised by a single, neutral colour (black-charcoal-grey, offwhite or brown), with occasional hues of green, blue, pink or yellow, and is accompanied by cracks and fractures, pits and cavities. Breaking the brittle matrix usually revealed a brighter and shinier internal structure (for example, a charcoal exterior would be accompanied by an anthracite-looking interior).

147 Samples (a) through to $(\mathrm{f})$ in Figure 3 are of similar dimensions but exhibit decreasing roundness and increasing angulation and roughness and an accompanying increase in apparent degree of association of the melted matrix with extraneous material. The more rounded pyroplastics of any 
sphericity (but usually high) that appear to contain relatively little agglomerated extraneous material (similar to samples (a) to (c)) could be considered as singular entities or "plastic pebbles", while more angular pyroplastics of generally low sphericity (similar to samples (d) to (f)) could be described better as "plastiglomerates". Agglomerated extraneous material is mainly plastic, and includes pellets, remains of straws, food packaging, bottle tops and rope, and fragments of unknown origin. Extraneous plastics of varied colours and shapes may be bonded (or fused) to the surface of the matrix or partially encapsulated, and may be intact or partly melted themselves.

Despite this classification, there is clearly a continuum of pyroplastics that makes distinction imprecise; moreover, occasional samples have additional characteristic features. For example, a few pebble-like pyroplastics had long filamentous plastic fragments fused at one end to the matrix (Figure S2), while some large plastiglomerates were extremely flat and rough and appeared to be composed of multiple matrices of different (but mainly neutral) colours or textures.

Table 1: Summary statistics defining the mass and dimensions of the pyroplastic samples from Whitsand Bay $(n=165)$.

\begin{tabular}{lrrrr}
\hline & mass, $\mathrm{g}$ & \multicolumn{1}{c}{$d_{1}, \mathrm{~mm}$} & $d_{2}, \mathrm{~mm}$ & \multicolumn{1}{c}{$d_{1} / d_{2}$} \\
\hline median & 0.358 & 12.9 & 6.58 & 2.04 \\
minimum & 0.097 & 5.64 & 3.72 & 0.422 \\
maximum & 274 & 240 & 40 & 7.50 \\
kurtosis & 69.9 & 31.6 & 6.18 & 11.3 \\
skewness & 7.61 & 4.88 & 2.39 & 2.82 \\
\hline
\end{tabular}

Table 1 shows summary statistics defining the mass and dimensions of the subset of 165 pyroplastics supplied from the beaches of Whitsand Bay. Distributions of all measures were skewed to the right with heavy tails or outliers. Mass ranged from less than $100 \mathrm{mg}$ to about $270 \mathrm{~g}$, with a median value that was about $350 \mathrm{mg}$ and a distribution that was bimodal (with relatively few clasts between 5 and $10 \mathrm{~g}$ ). Primary diameter $\left(d_{1}\right)$ ranged from about 6 to $240 \mathrm{~mm}$ (median $=12.9 \mathrm{~mm}$ ) and secondary diameter $\left(d_{2}\right)$ ranged from about 4 to $40 \mathrm{~mm}$ (median $=6.6 \mathrm{~mm}$ ), with the two measures combined to give aspect ratios $\left(d_{1} / d_{2}\right)$ ranging from 0.42 to 7.5 (median $=2.0$ ). In general, higher aspect ratios were accompanied by more angular plastiglomerates that appeared to contain relatively high quantities of visible extraneous agglomerated plastics while lower aspect ratios were associated with rounded pebbles containing relatively few (or no) visible extraneous plastics.

All pyroplastics were less dense than water at room temperature with the exception of five relatively large clasts. Three of the latter samples were plastiglomerates that had extensive and curved 

accumulations of calcareous deposits from the tube-building worm, Spirobranchus triqueter, on at least one face, with matted patches of what appeared to be the bryozoan, Electra pilosa, attached to one sample. The remaining two denser clasts were smooth and pebble-like with no visible extraneous material on their surfaces.

\subsection{Chemical characteristics}

Spectra arising from ATR-FTIR analysis of different regions of selected pyroplastics, and as exemplified in Figure 4, revealed that the polymeric matrix consisted of either (or both) polyethylene or polypropylene, even in samples that were denser than tap water. FTIR results also suggested the presence of non-aromatic plasticisers and terminal methyl groups (indicative of chain breakage) in many cases, but no clear spectral differences were evident between the surface and interior of any sample tested.

XRF analysis of the entire subset of samples from Whitsand Bay indicated that no pyroplastics were constructed in whole of polyvinyl chloride (PVC), but that one distinctive object encapsulated by a large plastiglomerate was PVC-based. XRF also revealed a variety of elements indicative of polymeric additives and residues and small quantities of inorganic extraneous matter (e.g. sand) in some cases. Concentrations of elements in the central surface region of the melted matrix (or in highly agglomerated samples, the most abundant matrix material) are shown in Table 2. Here, the number of cases in which each element was detected is shown along with an indicative range of detection limits (which vary for a given element dependent on sample thickness and composition), while statistical parameters are the same as those reported in Table 1.

Table 2: Detection frequency, indicative limit of detection (LOD) and concentration summary statistics for the elements in the pyroplastic samples from Whitsand Bay $(n=165)$. Also shown are the number of cases in which elemental concentrations exceed or potentially exceed their corresponding Restriction of Hazardous Substances (RoHS) limits ( $\mathrm{Br}$ as certain brominated compounds $700 \mu \mathrm{g} \mathrm{g}^{-1} ; \mathrm{Cd}=100 \mu \mathrm{g} \mathrm{g}^{-1}, \mathrm{Cr}$ and $\left.\mathrm{Pb}=1000 \mu \mathrm{g} \mathrm{g}^{-1}\right)$.

\begin{tabular}{lcccccccc}
\hline & $\mathrm{Br}$ & $\mathrm{Cd}$ & $\mathrm{Cr}$ & $\mathrm{Cu}$ & $\mathrm{Fe}$ & $\mathrm{Pb}$ & $\mathrm{Sb}$ & $\mathrm{Zn}$ \\
\hline no. detected & 120 & 46 & 72 & 93 & 165 & 128 & 12 & 137 \\
$\mathrm{LOD} \mu \mathrm{g} \mathrm{g}^{-1}$ & $5-10$ & $10-30$ & $10-15$ & $15-30$ & $30-60$ & $10-30$ & $20-40$ & $10-30$ \\
median, $\mu \mathrm{g} \mathrm{g}^{-1}$ & 7.8 & 62.4 & 53.5 & 31.4 & 773 & 76.0 & 54.8 & 62.3 \\
minimum, $\mathrm{g} \mathrm{g} \mathrm{g}^{-1}$ & 2.9 & 14.9 & 17.4 & 11.8 & 34.2 & 5.1 & 27.0 & 11.0 \\
maximum, $\mathrm{g} \mathrm{g} \mathrm{g}^{-1}$ & 346 & 1100 & 1430 & 581 & 45600 & 7510 & 196 & 2720 \\
kurtosis & 37.0 & 17.8 & 15.4 & 39.9 & 56.5 & 46.2 & -0.83 & 24.5 \\
skewness & 5.71 & 3.89 & 3.52 & 5.59 & 7.05 & 5.98 & 0.95 & 4.84 \\
no. exceeding RoHS & 0 & 18 & 1 & & & 13 & & \\
\hline
\end{tabular}


Percentage detection ranged from about 7 for $\mathrm{Sb}$ to 100 for $\mathrm{Fe}$, and median concentrations are greatest for $\mathrm{Fe}$, lowest for $\mathrm{Sb}$ and similar among the remaining elements. Concentrations of each element are highly variable and span up to three orders of magnitude, and with the exception of $\mathrm{Sb}$, distributions exhibit considerable skewness to the right and have heavy tails or outliers. Pearson's moment correlation analysis revealed that statistically significant relationships $(p<0.05)$ were restricted to the following elemental pairs: $\mathrm{Cd}-\mathrm{Sb}, \mathrm{Cr}-\mathrm{Pb}$ and $\mathrm{Cd}-\mathrm{Fe}$; with the greatest number of coassociations and the strongest correlation between $\mathrm{Cr}$ and $\mathrm{Pb}$ and as illustrated by the linear regression results in Figure 6.

XRF analysis of different areas of the same sample also resulted in variable results, and in particular where the matrix consisted of distinctly different components or colours or contained agglomerated material. Such heterogeneity is exemplified by the distributions of $\mathrm{Pb}$ and $\mathrm{Cr}$ concentrations in a large, multi-coloured plastiglomerate in Figure 6. However, when elemental concentrations were normalised with respect to concentrations of an element exhibiting some general co-association or correlation (such as $\mathrm{Pb}$ and $\mathrm{Cr}$; see above), ratios were rather consistent, as exemplified by the relationship inset in Figure 5.

Lead was also detected in the calcareous tubes of $S$. triqueter attached to the plastiglomerate illustrated in Figure 6 with a mean concentration of $12.2 \mu \mathrm{g} \mathrm{g}^{-1}$. By comparison, the mean $\mathrm{Pb}$ concentration in the worm tubes scraped from a pyroplastic whose $\mathrm{Pb}$ content was $<50 \mu \mathrm{g} \mathrm{g}^{-1}$ was $8.5 \mathrm{\mu g} \mathrm{g}^{-1}$ (but with no statistical difference noted between the mean tube concentrations according to a two-sample $t$-test; $p=0.078$ ) and $\mathrm{Pb}$ in the tubes on a beached tarball was always below the detection limit of about $6 \mu \mathrm{g} \mathrm{g}^{-1}$.

\section{Discussion}

Pyroplastics are evidently formed from melting or burning of plastic and are distinctly different from manufactured (primary and secondary) marine plastics in terms of origin, appearance and thickness. Since pyroplastics have been retrieved by colleagues from Atlantic beaches in Spain and Pacific beaches of Vancouver, they are not a regional phenomenon, and it is suspected that their distribution may be widespread but that documentation is lacking because of a distinctly geogenic appearance. It is likely that the samples described here are related to the plastiglomerates reported on Hawaiian beaches by Corcoran et al. (2014), but a key difference is bulk density, with those retrieved from Hawaii agglomerating rocks and stones rather than other plastics. We did not observe significant agglomeration of dense material but it is possible that such clasts are more abundant on 
the seafloor offshore. Several of the densest pyroplastics reported here returned relatively high concentrations of $\mathrm{Fe}$, suggesting agglomeration of sand, and were partially covered in calcareous tubes of $S$. triqueter. The latter observation, coupled with the absence of more delicate fouling species, is consistent with a period submerged in the circalittoral zone that is subject to movement and disturbance through tidal and wave action.

The sources of pyroplastics are unclear but there are a number of possibilities. Corcoran et al. (2014) attribute plastiglomerate formation to the in situ burning of plastic and other waste in bonfires on beaches or rocky outcrops, with smaller clasts then formed by mechanical disintegration. There is clear evidence of bonfires on the beaches of Whitsand Bay, with encrustations of burned plastic on rocks towards the cliffs. It is suspected that fires are used as campfires or barbeques, or are employed to deliberately but informally burn beach waste or spent fishing equipment. This source is consistent with the occurrence of identifiable remnants of plastics typical of the marine environment, like nurdles and netting, agglomerated into pyroplastics, and could also introduce extraneous matter like sand and wood into the matrix.

More organised burning of waste, including plastics, appears to take place on many small islands where limited or primitive facilities for waste disposal exist. For example, inhabitants of some Caribbean islands are known to burn waste that results in partially melted plastics entering the sea (Witherington and Witherington, 2011). Although the fetch of Whitsand Bay to the south west extends across the North Atlantic, closer to Cornwall it has been reported that domestic waste burnt in open fires on the Channel Island of Sark ( $170 \mathrm{~km}$ south east of Whitsand Bay) has been dumped at sea from the harbour wall (Delaney, 2018). In such cases, pyroplastics would be expected to contain a more diverse array of plastics from the domestic waste stream, with possible agglomeration of buoyant marine plastics if material had not fully cooled on disposal.

In England there are about 20,000 landfills that had been constructed before the Control of Pollution Act in 1974, with many located on low value coastal land (O'Shea et al., 2016). Being poorly engineered, leakage of chemicals and materials has frequently been reported through both erosion and collapse (Pope et al., 2011; Njue et al., 2012). It is possible, therefore, that partially burned plastic dumped in historical coastal landfills or resulting from the more general burning of bulk waste and organic matter before disposal is able to escape into the littoral zone. Here, pyroplastics would be expected to be composed of an assortment of older domestic plastics but contain no marine litter. prohibited since the implementation of the MARPOL 73/78-Agreement/Annex V (Regulation for the 
Prevention of Pollution by Ship Waste) of 1989, although only ships of 400 gross tonnage and above are required to carry out a garbage management plan (Chen and Liu, 2013). Current protocols typically involve reducing the volume of shipborne plastic waste, often by shredding and partial melting, and disposal of residual material in port. However, the rationale for the MARPOL agreement suggests that previous practice may have involved the direct disposal of large quantities of melted plastic into the marine environment, with the composition of resulting pyroplastics largely reflecting the contents of ship waste.

Regardless of the sources of pyroplastics and whether they are generated in situ, at sea or on land, many of those of positive buoyancy will end up in the turbulent swash zone where they are shaped by mechanical abrasion into more rounded and geogenic-looking pebbles. Evading ready recognition on the strandline, they are not classified under any category of marine litter according to OSPAR (2010) guidelines and potentially result in underestimates of the plastic inventory on beaches. Moreover, their brittleness means that they are a ready source of secondary microplastics and nanoplastics through impaction and shattering (Efimova et al., 2018), a characteristic that may well explain the bimodal size distribution we have observed.

Presumably, the age of deposition of pyroplastics is related to the degree of erosion and roundness and apparent agglomeration, although there is no clear means of quantifying this effect. With respect to age of manufacture of the plastic itself, a qualitative assessment may be gained from the distribution of certain additives within the matrix. Specifically, there is both a high occurrence and concentration of cadmium and lead among the samples, and in particular in the well-rounded clasts. These heavy metals are either no longer used or are highly regulated in consumer, electrical and packaging plastics, although small quantities appear in various goods through the recycling of improperly sorted historic waste (Turner, 2018). Significantly, limits for $\mathrm{Cd}$ and $\mathrm{Pb}$ in electrical plastics, defined by the Restriction of Hazardous Substances (RoHS) Directive (European Parliament and Council, 2003) as $100 \mu \mathrm{g} \mathrm{g}^{-1}$ and $1000 \mu \mathrm{g} \mathrm{g}{ }^{-1}$, respectively, are exceeded in the pyroplastics analysed herein in 18 and 13 cases, respectively (Table 2 ).

Until a few decades ago, both $\mathrm{Cd}$ and Pb were used as heat and UV stabilisers in PVC and as pigments to colour most types of plastic. Given that PVC was absent among the pyroplastics and that there was no clear relationship between $\mathrm{Cd}$ or $\mathrm{Pb}$ and chloride (indicative of residual $\mathrm{PVC}$ ), we surmise that the metals are present in the samples as pigments. The principal pigment of $\mathrm{Pb}$ used in plastics was lead chromate $\left(\mathrm{PbCrO}_{4}\right)$, effecting a range of reds, yellows and greens with high tinting strength and opacity by either itself or on mixing with other compounds. Among the pyroplastics there was a strong correlation between $\mathrm{Pb}$ and $\mathrm{Cr}$ concentrations determined by XRF (Figure 5), with 
a gradient defining the linear regression of $\mathrm{Pb}$ versus $\mathrm{Cr}$ similar to the mass ratio of the metals in pure $\mathrm{PbCrO}_{4}(\sim 4)$; moreover, within the same sample, $\mathrm{Pb}$ and $\mathrm{Cr}$ exhibited a similar relationship that is exemplified for the pyroplastic shown in Figure 6. Despite the presence of brightly-coloured leaded (and likely, cadmium-based) pigments, the matrix of pyroplastics assumes a neutral appearance (and most commonly grey or charcoal) through the mixing of multiple colours and hues A simple laboratory test involving melting brightly coloured polyethylene fragments in a steel canister under a series of Bunsen burners and rapidly cooling the contents under tap water resulted in a dark grey plastic matrix encapsulating various coloured streaks, as illustrated in Figure S3.

Compared with contemporary consumer goods (Turner and Filella, 2017) and other beached plastics collected from the region that have undergone similar degrees of environmental exposure (Massos and Turner, 2017; Wallerstein et al., 2019) there is a distinct lack of bromine and antimony in the pyroplastics. Specifically, the median concentration of $\mathrm{Br}$ is $7.8 \mu \mathrm{g} \mathrm{g}^{-1}$, Sb was only detected in twelve pyroplastics, and $\mathrm{Br}$ and $\mathrm{Sb}$ co-existed in just seven samples. Given the principal use of bromine in plastics is as brominated flame retardants (BFRs) in electrical and electronic housings and insulation, and that BFRs are usually associated with antimony as a retardant synergist, there is little evidence of electrical and electronic waste among the pyroplastic samples, either directly or through the presence of recycled material. This may reflect the fact that many pyroplastics pre-date the introduction of brominated flame retardants (the 1960s; Janssen, 2005) or the general recycling of electronic plastic into consumer goods, a practice that is currently not legal but that is facilitated through a series of loopholes (Turner, 2018). Alternatively, it is possible that, because the presence of BFRs and $\mathrm{Sb}$ render plastic more difficult to burn, such materials are deliberately avoided in the first place or remain as more discrete (i.e. non-agglomerated) residues after burning. (Aside from its high density, this would also explain the absence of PVC in the beached pyroplastics, a material whose halogen content ensures an inherent flame retardancy.)

In addition to underestimating the stock of beached plastic and their propensity to readily form microplastics and nanoplastics, a concern of pyroplastics is the potential for heavy metals to be mobilised or enter the foodchain. The mobility of $\mathrm{Pb}$ was evaluated by determining its concentration in calcareous worm tubes on a lead-rich pyroplastic (illustrated in Figure 6), a lead-poor pyroplastic and a beached tarball containing no detectable lead. That mean $\mathrm{Pb}$ concentrations in the tubes were greatest on the lead-rich pyroplastic and not detected on the tarball suggests that there is potential for transfer of additives or residues in plastic to organisms that use the material as a substrate. A similar conclusion was reached by Jang et al. (2016) for marine mussels inhabiting styrofoam that accumulated the flame retardant, hexabromocyclodecane, from the matrix but further studies in this 
area are required in order to evaluate the significance of contaminant transfer from plastics more generally.

In summary, pyroplastics are a non-manufactured type of marine plastic litter that appear to be derived from the informal or more organised burning of waste that may take place in situ or ex situ. They typically consist of a neutrally-coloured matrix agglomerating more distinct pieces of plastic and other debris, but weathering in the circalittoral zone shapes material into geogenic-looking pebbles that readily evade detection during beach-cleaning. Pyroplastics require their own classification within the umbrella of marine litter, and are a source of finer plastic particulates through mechanical breakdown and a potential source of contaminants for organisms that inhabit or ingest them.

\section{Acknowledgements}

Justin Vingoe, Rosemary Hill, Martin Gray and Silvano Bem are thanked for supplying samples from Cornwall, Ireland, Orkney and Spain, respectively. We are grateful for technical assistance from $\mathrm{Mr}$ Sam Allder and Mr Andrew Tonkin (UoP), and graphical support from Mr Jamie Quinn (UoP). The study was funded in part by a Plymouth Marine Institute HEIF grant.

\section{References}

Barboza, L.G.A., Vethaak, A.D., Lavorante, B.R.B.O., Lundebye, A.K., Guilhermino, L., 2018. Marine microplastic debris: An emerging issue for food security, food safety and human health. Marine Pollution Bulletin 133, 336-348.

BGS, 1987. Land's End. Sheet 50N 06W, Sea Bed Sediments and Quaternary, Scale 1:250,000. British Geological Survey, Keyworth, UK.

Cai, L.Q., Wang, J.D., Peng, J.P., Wu, Z.Q., Tan, X.L., 2018. Observation of the degradation of three types of plastic pellets exposed to UV irradiation in three different environments. Science of the Total Environment 628/629, 740-747.

Chen, C.-L., Liu, T.-K., 2013. Fill the gap: Developing management strategies to control garbage pollution from fishing vessels. Marine Policy 40, 34-40.

Corcoran, P.L., Moore, C.J., Jazvac, K., 2014. An anthropogenic marker horizon in the future rock record. Geological Society of America Today, 24 (6) doi: 10.1130/GSAT-G198A.1.

Delaney, K., 2018. The Sark Newspaper, issue 207, May 2018.

http://www.sarknewspaper.com/Flippers/Sark\%20Newspaper\%2018\%20May\%202018/

Efimova, I., Bagaeva, M., Bagaev, A., Kileso, A., Chubarenko, I.P., 2018. Secondary microplastics generation in the sea swash zone with coarse bottom sediments: Laboratory experiments. Frontiers in Marine Science https://doi.org/10.3389/fmars.2018.00313 
European Parliament and Council, 2003. Directive 2002/95/EC on the restriction of the use of certain hazardous substances in electrical and electronic equipment. Official Journal of the European Union L37/19.

Jang, M., Shim, W.J., Han, G.M., Rani, M., Song, Y.K., Hong, S.H., 2016. Styrofoam debris as a source of hazardous additives for marine organisms. Environmental Science and Technology 50, 4951-4960.

Janssen, S., 2005. Brominated flame retardants: Rising levels of concern. Healthcare Without Harm, Arlington, VA, 33pp.

Krelling, A.P., Williams, A.T., Turra, A., 2017. Differences in perception and reaction of tourist groups to beach marine debris that can influence a loss of tourism revenue in coastal areas. Marine Policy 85, 87-99.

Massos, A., Turner, A., 2017. Cadmium, lead and bromine in beached microplastics. Environmental Pollution 227, 139-145.

Njue, C.N., Cundy, A.B., Smith, M., Green, I.D., Tomlinson, N., 2012. Assessing the impact of historical coastal landfill sites on sensitive ecosystems: A case study from Dorset, Southern England. Estuarine, Coastal and Shelf Science 114, 166-174.

O'Shea, F.T., Cundy, A., Spencer, K.L., 2016. The contaminant legacy from historic coastal landfills and their potential as sources of diffuse pollution. Marine Pollution Bulletin 128, 446-455.

OSPAR, 2010. Guideline for monitoring marine litter on the beaches in the OSPAR maritime area. OSPAR Commission, London, 84pp.

Pope, N.D., O'Hara, S.C.M., Imamura, M., Hutchinson, T.J., Langston, W.J., 2011. Influence of a collapsed coastal landfill on metal levels in sediments and biota-a portent for the future? Journal of Environmental Monitoring 13, 1961-1974.

Santillo, D., Miller, K., Johnston, P., 2017. Microplastics as contaminants in commercially important seafood species. Integrated Environmental Assessment and Management 13, 516-521.

Song, Y.K., Hong, S.H., Jang, M., Han, G.M., Jung, S.W., Shim, W.J., 2017. Combined effects of UV exposure duration and mechanical abrasion on microplastic fragmentation by polymer type. Environmental Science and Technology 51, 4368-4376.

Turner, A., 2018. Black plastics: linear and circular economies, hazardous additives and marine pollution. Environment International 117, 308-318.

Turner, A., Solman, K.R., 2016. Analysis of the elemental composition of marine litter by fieldportable-XRF. Talanta 159, 262-271.

Turner, A., Filella, M., 2017. Bromine in plastic consumer products - Evidence for the widespread recycling of electronic waste. Science of the Total Environment 601-602, 374-379.

Turner, A., Wallerstein, C., Arnold, R., 2019. Identification, origin and characteristics of bio-bead microplastics from beaches in western Europe. Science of the Total Environment 664, 938-947.

Uncles, R.J., Stephens, J.A., Harris, C., 2015. Physical processes in a coupled bay-estuary coastal system: Whitsand Bay and Plymouth Sound. Progress in Oceanography 137B, 360-384.

Wilcox, C., Mallos, N.J., Leonard, G.H., Rodriguez, A., Hardesty, B.D., 2016. Using expert elicitation to estimate the impacts of plastic pollution on marine wildlife. Marine Policy 65, 107-114. 
Witherington, B., Witherington, D., 2011. Living beaches of Georgia and the Carolinas: A

409 Beachcomber's guide. Pineapple Press, Sarasota FL, 342pp. 
410 Figure 1: Locations in Cornwall, south west England, where pyroplastics have been collected (filled 411 circles) in relation to major embayments and centres of population.
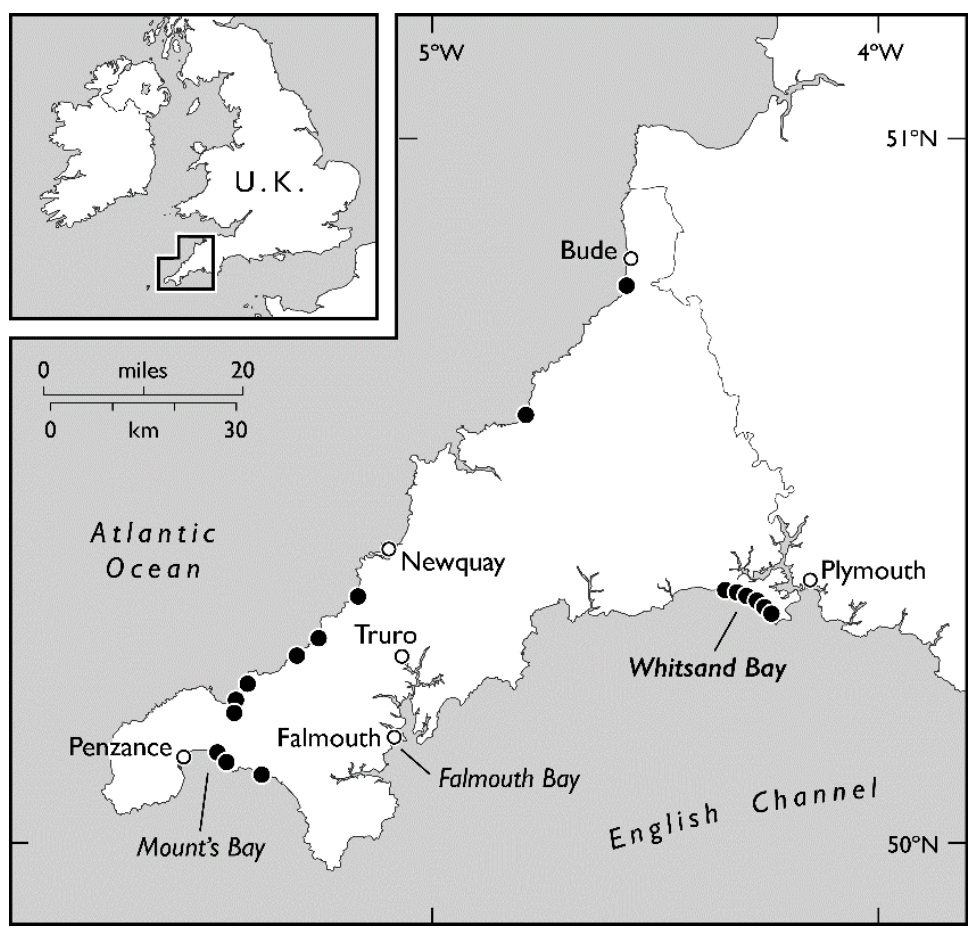
Figure 2: Pyroplastics retrieved from the strandline at Whitsand Bay.

413

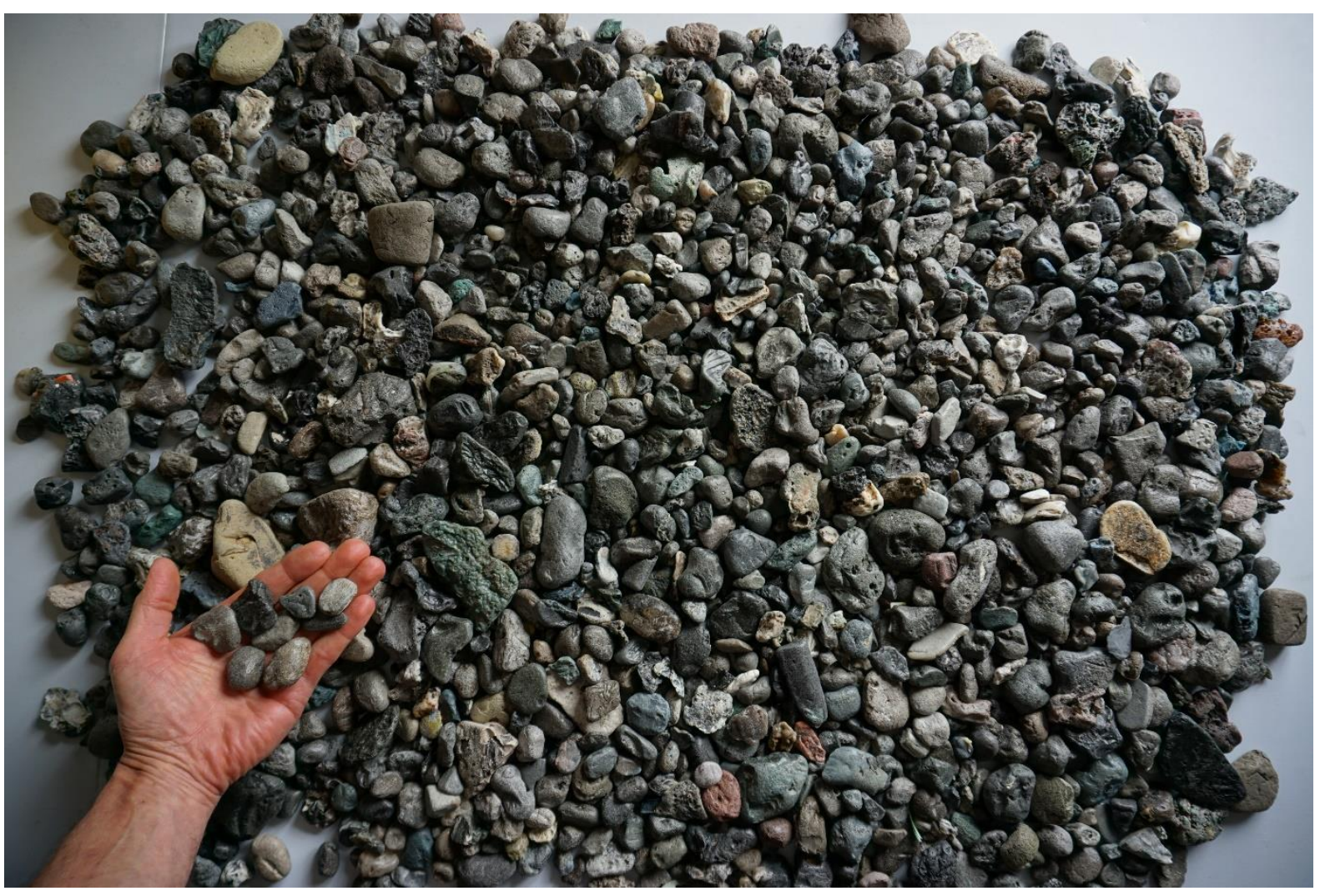


Figure 3: A selection of samples collected from Whitsand Bay exhibiting increasing agglomeration and angulation from (a) through to (f).

(a)

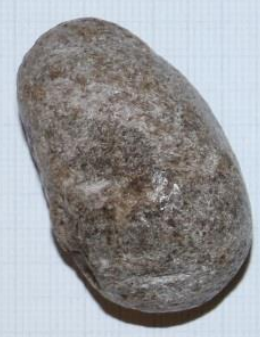

(d)

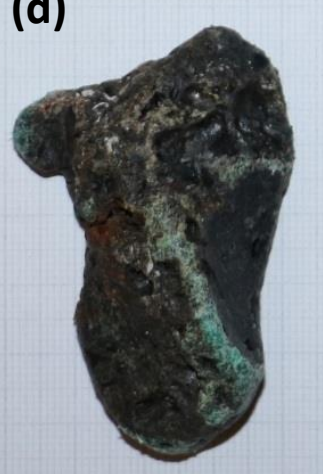

(b)

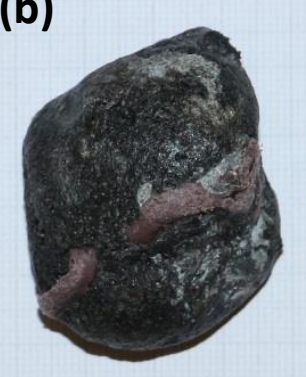

(e)

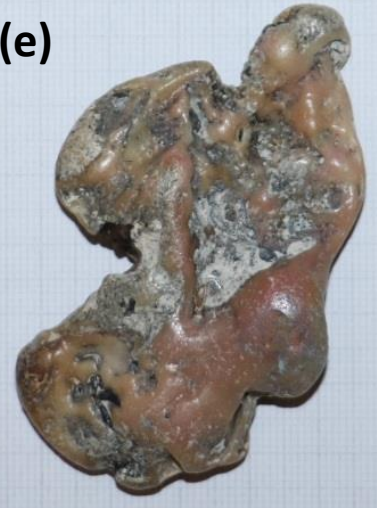

(c)

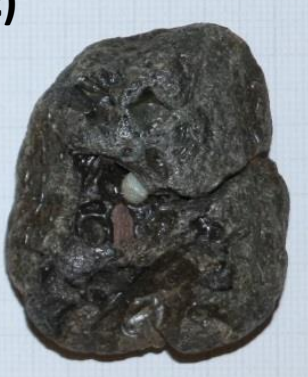

(f)

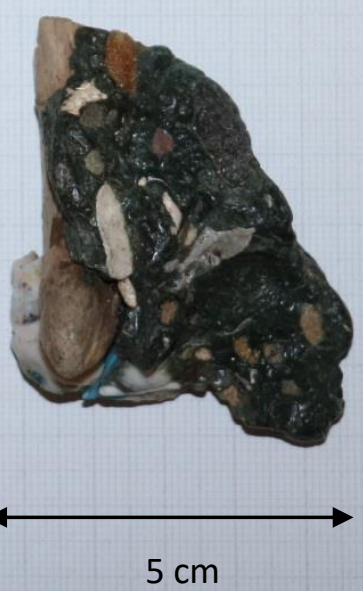



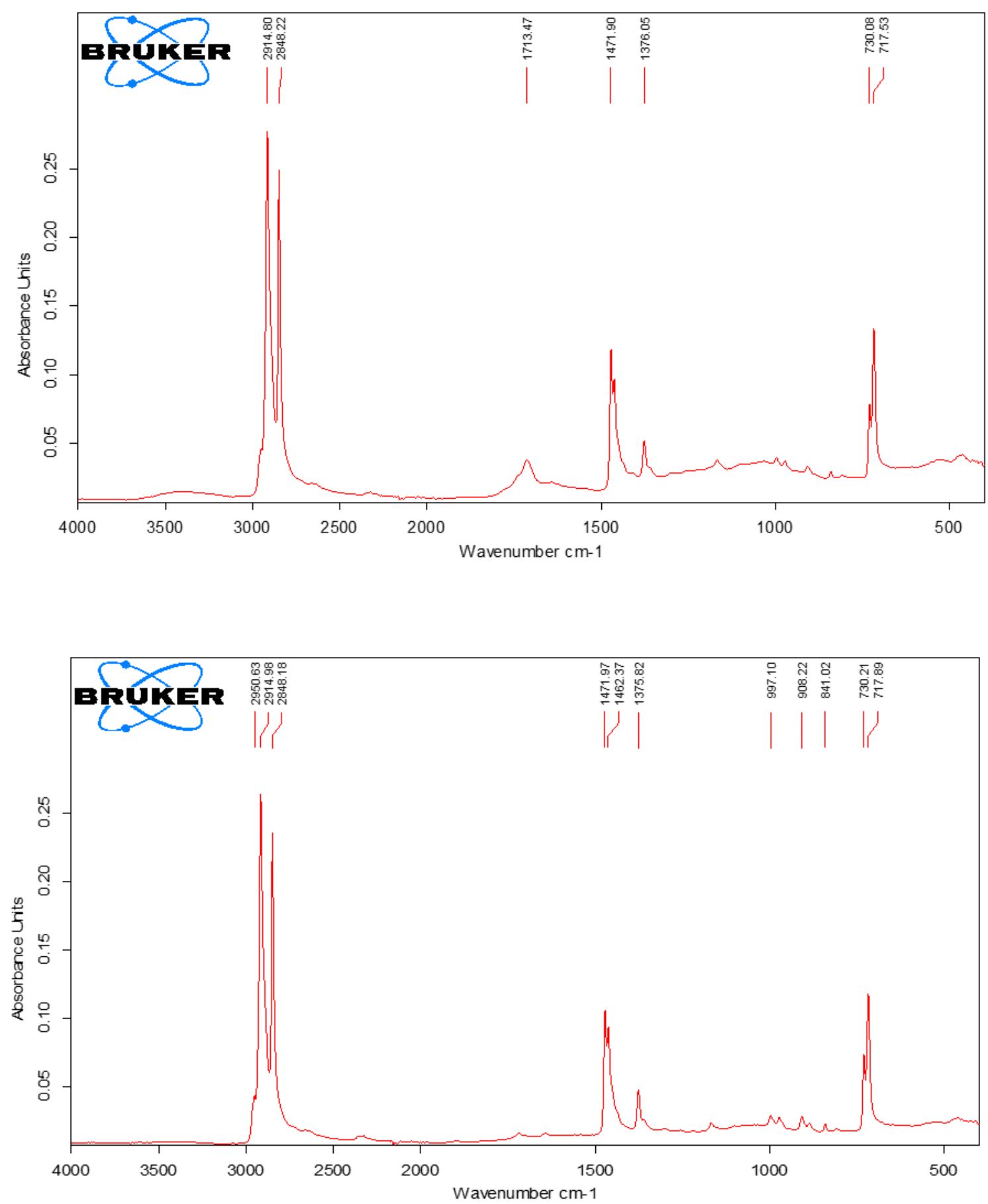
Figure 5: Relationship between $\mathrm{Pb}$ and $\mathrm{Cr}$ in the pyroplastics from Whitsand Bay. The statistical summary defines the linear regression of the data excluding data points with the highest $\mathrm{Pb}$ content and the highest $\mathrm{Cr}$ content (shown as open triangles).

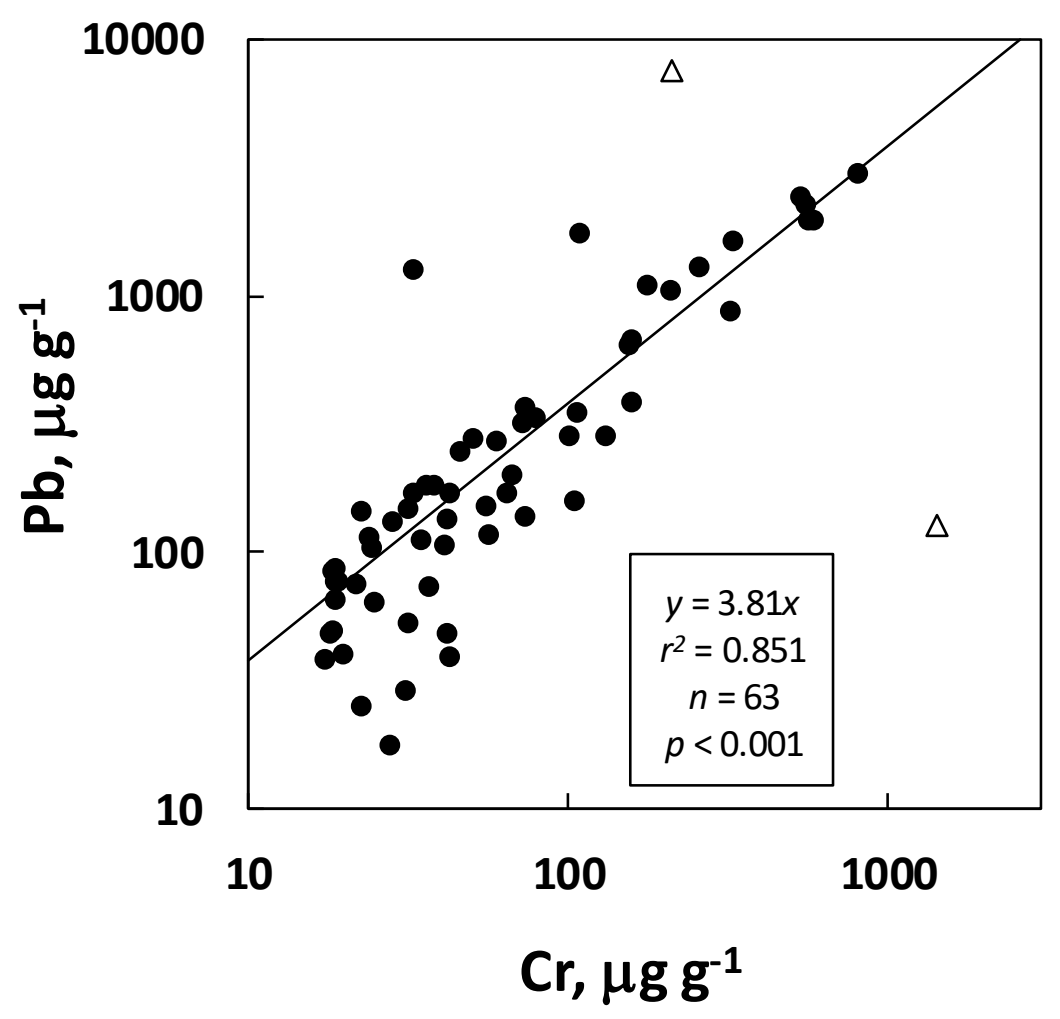

417

418

419

420

421 
Figure 6: Concentrations of $\mathrm{Pb}$ and $\mathrm{Cr}\left(\right.$ in $\mu \mathrm{g} \mathrm{g}^{-1}$ ) across different regions of a pyroplastic hosting calcareous deposits of the tube-building worm, $\mathrm{S}$. triqueter. Inset is the relationship between $\mathrm{Pb}$ and $\mathrm{Cr}$ concentrations in the sample.

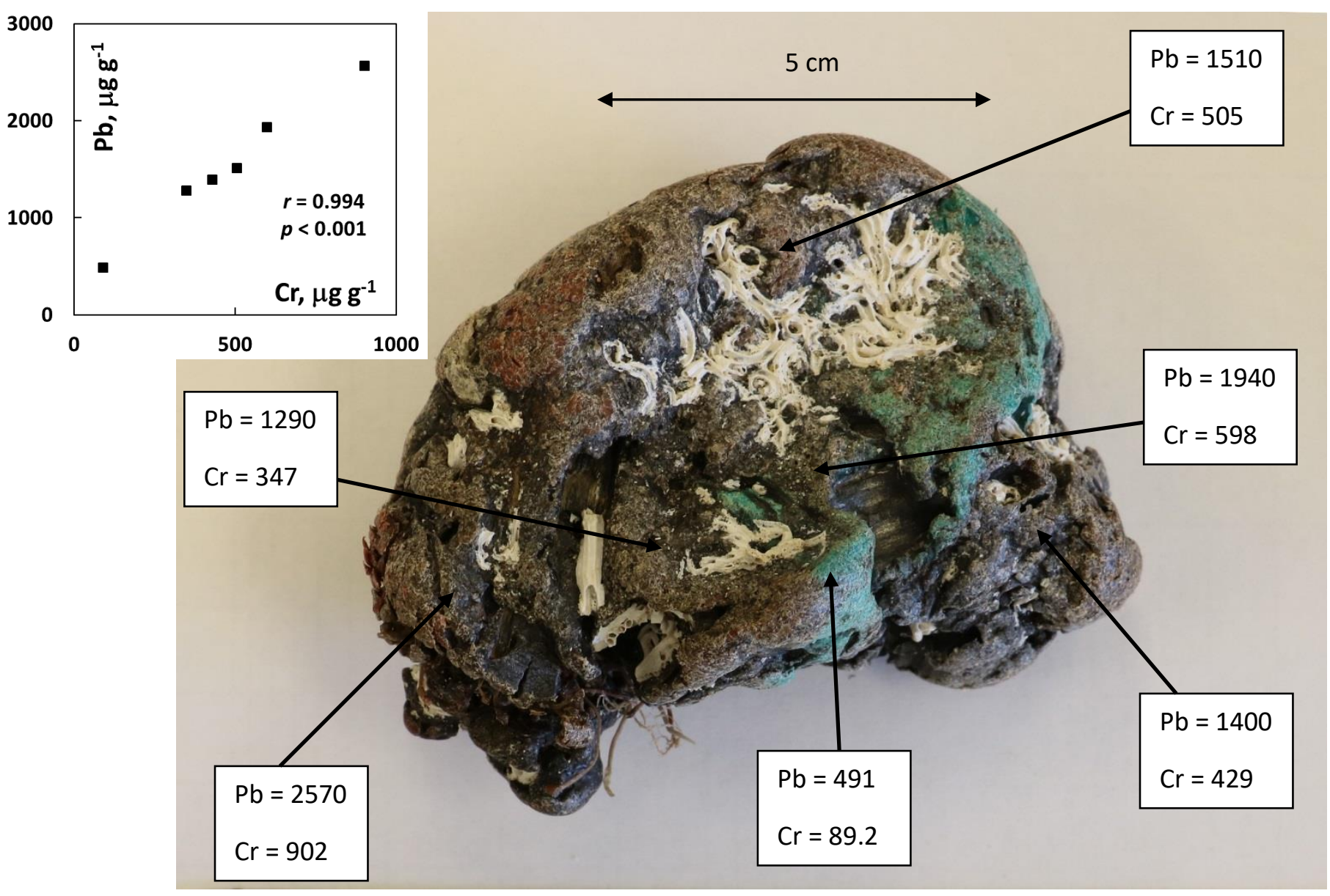


